\title{
Pre-existing Autoantibodies Neutralizing High Concentrations of Type I Interferons in Almost 10\% of COVID-19 Patients Admitted to Intensive Care in Barcelona
}

\author{
Xavier Solanich ${ }^{1,2}$ - Raúl Rigo-Bonnin ${ }^{2,3} \cdot$ Victor-David Gumucio ${ }^{2,4} \cdot$ Paul Bastard $^{5,6,7} \cdot$ Jérémie Rosain $^{5,6}$. \\ Quentin Philippot ${ }^{5,6} \cdot$ Xosé-Luis Perez-Fernandez $^{2,4}$. Maria-Paz Fuset-Cabanes ${ }^{2,4}$. Miguel-Ángel Gordillo-Benitez ${ }^{2,4}$. \\ Guillermo Suarez-Cuartin ${ }^{2,8}$ • Enric Boza-Hernandez $z^{2,9}$. Antoni Riera-Mestre ${ }^{1,2,10}$ • Alba Parra-Martínez ${ }^{11,12}$. \\ Roger Colobran ${ }^{13,14,15}$. Arnau Antoli ${ }^{12}$. Sergio Navarro ${ }^{2,16} \cdot$ Gemma Rocamora-Blanch $^{1,2} \cdot$ Mario Framil $^{2,16}$. \\ Laura Calatayud $^{2,17} \cdot$ Xavier Corbella $^{1,2,18}$. Jean-Laurent Casanova ${ }^{5,6,7,19} \cdot$ Francisco Morandeira $^{2,16}$. \\ Joan Sabater-Riera ${ }^{2,4}$
}

Received: 13 July 2021 / Accepted: 8 September 2021 / Published online: 27 September 2021

() The Author(s), under exclusive licence to Springer Science+Business Media, LLC, part of Springer Nature 2021

\begin{abstract}
Background It is important to predict which patients infected by SARS-CoV-2 are at higher risk of life-threatening COVID19. Several studies suggest that neutralizing auto-antibodies (auto-Abs) against type I interferons (IFNs) are predictive of critical COVID-19 pneumonia.

Objectives We aimed to test for auto-Abs to type I IFN and describe the main characteristics of COVID-19 patients admitted to intensive care depending on whether or not these auto-Abs are present.

Methods Retrospective analysis of all COVID-19 patients admitted to an intensive care unit (ICU) in whom samples were available, from March 2020 to March 2021, in Barcelona, Spain.

Results A total of 275 (70.5\%) out of 390 patients admitted to ICU were tested for type I IFNs auto-antibodies ( $\alpha 2$ and/or $\omega)$ by ELISA, being positive in $49(17.8 \%)$ of them. Blocking activity of plasma diluted 1/10 for high concentrations (10 ng/ $\mathrm{mL}$ ) of IFNs was proven in $26(9.5 \%)$ patients. Almost all the patients with neutralizing auto-Abs were men (92.3\%). ICU patients with positive results for neutralizing IFNs auto-Abs did not show relevant differences in demographic, comorbidities, clinical features, and mortality, when compared with those with negative results. Nevertheless, some laboratory tests (leukocytosis, neutrophilia, thrombocytosis) related with COVID-19 severity, as well as acute kidney injury (17 [65.4\%] vs. $100[40.2 \%] ; p=0.013$ ) were significantly higher in patients with auto-Abs.

Conclusion Auto-Abs neutralizing high concentrations of type I IFNs were found in $9.5 \%$ of patients admitted to the ICU for COVID-19 pneumonia in a hospital in Barcelona. These auto-Abs should be tested early upon diagnosis of SARS-CoV-2 infection, as they account for a significant proportion of life-threatening cases.
\end{abstract}

Keywords COVID-19 $\cdot$ SARS-CoV-2 $\cdot$ acute kidney injury $\cdot$ type I interferons $\cdot$ auto-antibodies

\begin{tabular}{|c|c|c|c|}
\hline Abbre & & ALT & Catalytic concentration of alanine \\
\hline $8-\mathrm{OS}$ & 8-Point ordinal scale & & transaminase in plasma \\
\hline AKI & Acute kidney injury & apH & $\mathrm{PH}$ in arterial blood \\
\hline ALB & Mass concentration of albumin in plasma & ARDS & Acute respiratory disease syndrome \\
\hline & & $\mathrm{aSatO}_{2}$ & $\begin{array}{l}\text { Substance fraction of oxygen in arterial } \\
\text { blood }\end{array}$ \\
\hline Xavier & nd Raúl Rigo-Bonnin are considered first co- & & transaminase in plasma \\
\hline & & auto-Abs & Auto-antibodies \\
\hline$\triangle \mathrm{Xa}$ & & BMI & Body mass index \\
\hline & llvitgehospital.cat & BIL & Substance concentration of bilirubin in \\
\hline Extend & formation available on the last page of the article & & pla \\
\hline
\end{tabular}




\begin{tabular}{|c|c|c|}
\hline 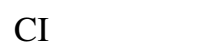 & onfidence interval & 3,3',5,5'-Tetramethylbenzidine \\
\hline $\mathrm{CoV}$ & oronavirus & Mass concentration of troponin $\mathrm{T}$ in \\
\hline DVID-19 & oronavirus disease 2019 & \\
\hline REA & & World Health Organization \\
\hline & asma & ntration of urea in plasma \\
\hline RP & $\begin{array}{l}\text { ass concentration of C-reactive protein } \\
\text { plasma }\end{array}$ & \\
\hline RRT & us renal replacement therapy & \multirow{3}{*}{ Introduction } \\
\hline $\mathrm{D}$ & D-dimer in plasma & \\
\hline VT & eep vein thrombosis & \\
\hline $\mathrm{CMO}$ & rane oxygenation & \multirow{7}{*}{$\begin{array}{l}\text { In December } 2019 \text {, an emerging disease (COVID-19), } \\
\text { caused by a newly identified human coronavirus (SARS- } \\
\text { CoV-2), was first recognized in Wuhan, China, and spread } \\
\text { worldwide }[1,2] \text {. The WHO declared the COVID-19 epi- } \\
\text { demic to be a pandemic on March } 12,2020 \text { [3], and it con- } \\
\text { tinues to spread globally, causing considerable morbimortal- } \\
\text { ity and economic damage. }\end{array}$} \\
\hline ERRI & ferritin in plasma & \\
\hline $\mathrm{iO}_{2}$ & action of inspired oxygen & \\
\hline FR & filtration rate & \\
\hline $\mathrm{PE}$ & sa & \\
\hline RP & sh peroxidase & \\
\hline UB & ellvitge & \\
\hline $\mathrm{CU}$ & it & \multirow{3}{*}{$\begin{array}{l}\text { Age is the greatest risk factor for life-threatening COVID- } \\
19 \text { pneumonia [4], and other epidemiological risk factors } \\
\text { (men gender, obesity, diabetes, common genetic variants...) } \\
\text { can contribute but with a modest effects [5-8]. These con- }\end{array}$} \\
\hline $\mathrm{L}$ & $n$ & \\
\hline L6 & $\begin{array}{l}\text { ass concentration of interleukin- } 6 \text { in } \\
\text { sma }\end{array}$ & \\
\hline FNs & & \multirow{9}{*}{$\begin{array}{l}\text { ditions do not allow physicians to accurately predict which } \\
\text { patients infected by SARS-CoV-2 are at risk to transit into } \\
\text { the most severe stages of COVID- } 19 \text {. } \\
\text { Type I interferons (IFNs) are a family of cytokines that } \\
\text { mediate the early innate immune response to viral infections } \\
\text { limiting viral spread. When SARS-CoV-2 enters human } \\
\text { cells, its viral RNA is recognized by endosomal Toll-like } \\
\text { receptors such as TLR } 3 \text { and TLR7, as well as cytosolic } \\
\text { MDA-5, which drive a pathway that leads to gene expres- } \\
\text { sion of type I IFNs }[5,9] \text {. }\end{array}$} \\
\hline $\mathrm{FN}-\alpha 2$ & & \\
\hline $\mathrm{FN}-\gamma$ & & \\
\hline $\mathrm{FN}-\omega$ & & \\
\hline $\mathrm{gG}$ & $\mathrm{G}$ & \\
\hline IMV & lation & \\
\hline $\mathrm{QR}$ & & \\
\hline$V$ & & \\
\hline KDIGO & $\begin{array}{l}\text { Disease Improving Global } \\
\text { es }\end{array}$ & \\
\hline EU & oncentration of leucocytes in & \multirow{4}{*}{$\begin{array}{l}\text { In the past months, several human genetic variants associ- } \\
\text { ated with higher viral binding and entry have been identified, } \\
\text { as well as genes related to higher COVID-19 severity [10, } \\
\text { 11]. In addition, rare deleterious variants impairing TLR3- } \\
\text { and TLR7-driven type I IFNs induction via IRF7 and ampli- } \\
\text { fication via IFNAR1 have been identified in about 5\% of } \\
\text { life-threatening COVID-19 cases younger than } 60 \text { years [12, } \\
\text { Asano in press]. }\end{array}$} \\
\hline $\mathrm{DH}$ & $\begin{array}{l}\text { talytic concentration of lactate dehydro- } \\
\text { nase in plasma }\end{array}$ & \\
\hline YM & $\begin{array}{l}\text { Imber concentration of lymphocytes in } \\
\text { ood }\end{array}$ & \\
\hline JEU & mber concentration of neutrophils in & \\
\hline OR & Ids ratio & \multirow{9}{*}{$\begin{array}{l}\text { Recently, an international consortium reported that } 101 \text { of } \\
987 \text { patients (10.2\%) with life-threatening COVID- } 19 \text { pneu- } \\
\text { monia had neutralizing auto-antibodies (auto-Abs) against } \\
\text { type I IFNs (IFN- } \alpha 2 \text {, IFN- } \omega \text {, or both) [13]. All of the patients } \\
\text { tested had low or undetectable serum IFN- } \alpha \text { values during } \\
\text { acute disease. Interestingly, these auto-Abs were present } \\
\text { before SARS-CoV-2 pandemic in the patients tested. None- } \\
\text { theless, these antibodies were absent in } 663 \text { individuals with } \\
\text { asymptomatic or mild SARSCoV-2 infection. Half of these } \\
\text { patients were over } 65 \text { years old, and notably, } 95 \text { ( } 94 \% \text { of the } \\
101 \text { patients with auto-Abs were men. More recently, it was } \\
\text { found that auto-abs neutralizing } 100 \text {-fold lower concentra- } \\
\text { tions of type I IFN were more frequent, found in about } 15 \% \\
\text { of critical cases (Bastard in press). }\end{array}$} \\
\hline $\mathrm{paCO}_{2}$ & $\begin{array}{l}\text { rtial pressure of carbon dioxide in arte- } \\
\text { l blood }\end{array}$ & \\
\hline $\mathrm{paO}_{2}$ & rtial pressure of oxygen in arterial blood & \\
\hline $\mathrm{BS}$ & & \\
\hline PLT & $\begin{array}{l}\text { umber concentration of platelets in } \\
\text { ood }\end{array}$ & \\
\hline PROCAL & $\begin{array}{l}\text { Iass concentration of procalcitonin in } \\
\text { asma }\end{array}$ & \\
\hline T & lative time of prothrombin in plasma & \\
\hline रT- & $\begin{array}{l}\text { everse transcription polymerase chain } \\
\text { eaction }\end{array}$ & \\
\hline $\mathrm{AK}$ & $\begin{array}{l}\text { Severe acute respiratory syndrome corona- } \\
\text { irus } 2\end{array}$ & \\
\hline
\end{tabular}


These findings may provide a first explanation for the excess of older men among patients with life-threatening COVID-19. Furthermore, they might also offer a means in identifying individuals at-risk of evolving into severe or critical stage of COVID-19 [5], as it has been replicated worldwide [14-17]. In addition, the detection of neutralizing auto-Abs against type I IFNs is technically straightforward and not expensive, so that it could be advantageous to apply in routine clinical practice. Finally, these findings might also pave the way for prevention and treatment by using plasmapheresis, plasmablast depletion, or recombinant type I IFNs not targeted by the auto-Abs (e.g., IFN- $\beta$ ) [18-20].

In the present study, we aimed to describe clinical, analytical, and evolutive data of life-threatening COVID-19 patients admitted to the ICU depending on whether or not auto-Abs neutralizing high concentrations of type I IFNs are present.

\section{Methods}

\section{Study Design and Patients}

This study was conducted at the Hospital Universitari de Bellvitge (HUB), a 750-bed tertiary-care public hospital for adults in Barcelona, Spain. HUB is the referral hospital for 2 million inhabitants with high-complexity diseases from the Southern area of Catalonia. We performed a retrospective study of COVID-19 patients admitted to the ICU during the first year of the pandemic (from March 2020 to March 2021) in whom samples were available. SARS-CoV-2 infection was confirmed by RT-PCR in all patients.

Data were obtained from routine daily practice and anonymized. Personal and clinical data were collected in accordance with the Spanish Data Protection Act (Ley Orgánica 3/2018 de 5 de diciembre de Protección de Datos Personales). Informed consent was waived due to the study's retrospective nature, and the mandatory isolation measures applied during in-hospital care. The protocol was approved by the Ethics Committee of the Hospital Universitari de Bellvitge (Barcelona, Spain; approval number PR40/21).

\section{Clinical and Laboratory Variables}

Demographic data and main comorbidities were collected from each patient. Laboratory data were registered at admission to the ICU. The WHO 8-point ordinal scale was calculated in each participant (https://www.who.int/blueprint/ priority-diseases/key-action/COVID-19_Treatment_Trial_ Design_Master_Protocol_synopsis_Final_18022020.pdf). Complications were documented as follows: (1) Thrombotic complications included deep vein thrombosis (DVT), pulmonary embolism (PE), myocardial infarction, mesenteric ischemia, lower limb ischemia, cerebral ischemic attack confirmed by an imaging study; (2) Hemorrhagic complications included major bleeding according to the definition of the International Society on Thrombosis and Haemostasis [21]; (3) Cardiovascular complications included no coronary heart disease (heart failure, arrhythmias, myocarditis); (4) Acute kidney injury (AKI) was defined using the Kidney Disease Improving Global Outcomes (KDIGO) staging. So, patients were classified as stage 1 if they present an increase of concentration of creatinine in plasma (CREA) of $26.5 \mu \mathrm{mol} / \mathrm{L}$ within $48 \mathrm{~h}$, or increase in CREA $\geq 1.5$ times baseline, which is known or presumed to have occurred within the prior 7 days; stage 2 AKI was considered when CREA increase 2.0 to 2.9 times baseline; and stage $3 \mathrm{AKI}$, when CREA increase $\geq 3.0$ times baseline or increase in CREA to $\geq 353.6 \mu \mathrm{mol} / \mathrm{L}$, or the initiation of renal replacement therapy (RRT), or in patients $<18$ years a decrease in eGFR to $<35 \mathrm{~mL} / \mathrm{min} / 1.73 \mathrm{~m}^{2}$ [22]; (5) Superinfection included a second infection with a bacterial agent at the time or during ICU admission; (6) Sepsis was defined as an increase in the Sequential (sepsis-related) Organ Failure Assessment (SOFA) score of 2 points or more with respect to baseline SOFA; and (7) Septic shock was identified by a vasopressor requirement to maintain a mean arterial pressure of $65 \mathrm{mmHg}$ or greater and serum lactate level greater than $2 \mathrm{mmol} / \mathrm{L}$ (>18 mg/dL) in the absence of hypovolemia [23]; (8) Multiple organ failure was defined as the SOFA score alteration of two or more organs with a score of $\geq 3$ [24]. Treatments specifically used to treat COVID-19, mechanical ventilation duration and other organ support during ICU stay as vasopressors, RRT, nitric oxide, and extracorporeal membrane oxygenation (ECMO) were also analyzed. Length of hospital and ICU stay and death during hospitalization were also recorded. All drugs and procedures were used according to HUB protocol which is detailed in the supplementary materials.

\section{Auto-Abs Against Type I IFNs}

Analysis of auto-Abs against type I IFNs (IFN- $\alpha 2$ and IFN$\omega)$ were performed using an ELISA technique according to St. Giles procedure [13]. In brief, NUNC MaxiSorp ${ }^{\mathrm{TM}}$ high protein-binding capacity 96 well ELISA plates (Thermo Fisher Scientific Inc., Waltham, MA, USA) were coated with recombinant human IFN- $\alpha 2$ or IFN- $\omega$ by incubation of the diluted cytokine in $100 \mu \mathrm{L}$ of coating buffer $(1 \mathrm{mg} / \mathrm{L})$ overnight at $4^{\circ} \mathrm{C}$. Plates were washed three times with PBS, blocked by incubation with PBS supplemented with $5 \%$ nonfat milk powder $1 \mathrm{~h}$ at room temperature on an agitator, washed again with PBS-Tween $0.005 \%(\mathrm{v} / \mathrm{v})$, and incubated with $100 \mu \mathrm{L}$ of 1:50 dilution of serum samples from patients or controls in HPE dilution buffer (Sanquin, Amsterdam, The Netherlands) for $2 \mathrm{~h}$ at room temperature 
in the agitator. After wash, Fc-specific HRP-conjugated $\mathrm{IgG}$ fractions of polyclonal goat antiserum against human IgG (Nordic-MUbio, Susteren, The Netherlands) were added to a final concentration of $2 \mathrm{mg} / \mathrm{L}$. Plates were incubated for $1 \mathrm{~h}$ at room temperature and washed. Then, substrate (TMB) was added and incubated $10 \mathrm{~min}$. The reaction was stopped by adding $\mathrm{H}_{2} \mathrm{SO}_{4} 0.18 \mathrm{M}$, and optical density at $450 \mathrm{~nm}$ was measured. We considered as positive results of both auto-Abs against type I IFNs any result greater than a cutoff value calculated as the mean value plus two standard deviations of a control group of healthy non-COVID-19 patients with a similar age and gender.

\section{Neutralizing Auto-Abs Against Type I IFNs}

The neutralizing ability in vitro of anti-Abs against IFN- $\alpha 2$ and anti-IFN- $\omega$, i.e., their blocking activity, was determined by assessing a reporter luciferase activity [13]. Briefly, HEK293T cells were transfected with the firefly luciferase plasmids under the control of human ISRE promoters in the pGL4.45 backbone, and a constitutively expressing Renilla luciferase plasmid for normalization (pRL-SV40). Next, cells were transfected in the presence of the X-tremeGene 9 transfection reagent (MilliporeSigma, Burlington, MA, USA) for $36 \mathrm{~h}$. Then, Dulbecco's modified Eagle medium (DMEM, Thermo Fisher Scientific) medium supplemented with $10 \%$ healthy control or patient serum/plasma and were either left unstimulated or were stimulated with IFN- $\alpha 2$ or IFN- $\omega(10 \mathrm{ng} / \mathrm{mL})$ for $16 \mathrm{~h}$ at $37^{\circ} \mathrm{C}$. Each sample was tested once. Finally, luciferase levels were measured with the Dual-Glo reagent, according to the manufacturer's protocol (Promega Corp., Madison, WI, USA). Firefly luciferase values were normalized against Renilla luciferase values.

\section{Statistical Analysis}

Continuous variables were presented as the median and interquartile range (IQR) and categorical data as frequency rates and percentages. Comparisons of the cohorts were made using a chi-square test or Fisher's exact test for categorical variables and a Mann-Whitney $U$ test for continuous or ordinal variables. From June 2020, there were significant changes in the treatment of COVID-19 patients, and for this reason, it has been performed a subanalysis of these two periods (first wave vs. second/third wave in Spain). Statistical significance was defined as $p$-value $<0.05$, and we also used odds ratios (OR) and their $95 \%$ confidence intervals (CI) for categorical variables. Calculations were performed with the statistical package SPSS version 19 (IBM Corp. Endicott, NY, USA).

\section{Results}

From March 10, 2020, to March 6, 2021, 3216 COVID-19 patients were hospitalized at our hospital, and 390 (12.1\%) were admitted to the ICU due to respiratory failure. Of them, 275 (70.5\%) ICU patients had frozen serum samples stored in the HUB immunology department, and type I IFNs auto-Abs could be tested.

Main characteristics of all included patients are shown in Tables 1, 2, and 3. Patients included belonged to the different epidemic waves (first 125 [45.4\%], second 23 [8.4\%], and third 127 [46.2\%]). Overall, the median age was 64 years old (IQR 55-71), and male gender represented $76.7 \%$ of all patients. The most prevalent preexisting comorbidities were hypertension $(53.1 \%)$, obesity (49.8\%), dyslipidemia (49.1\%), and diabetes mellitus $(28.4 \%)$. The median number of days from the appearance of clinical symptoms to admission to the hospital was 8 (IQR 6-11), and later with a median of 2 (IQR 0-6) days, they were admitted to the ICU. The main laboratory parameters at ICU admission showed a median of 0.64 (IQR $0.38-0.96$ ) lymphocytes $\times 10^{9}$ cells/L, a median LDH of 471.5 (IQR 367.5-610.8) U/L, a median CRP of 136.1 (IQR 52.8-238.3) $\mathrm{mg} / \mathrm{L}$, a median ferritin of 1495 (874-2325) $\mathrm{mg} / \mathrm{L}$, and a median d-dimer of 879 (454-2862) $\mu \mathrm{g} / \mathrm{L}$. The median $p \mathrm{aO}_{2} / \mathrm{FiO}_{2}$ at ICU admission was 116.5 (IQR $86-166) \mathrm{mmHg} / \%$. Overall, 38 (13.8\%) patients belonged to group 5 of the WHO 8-point ordinal scale, $78(28.4 \%)$ to group $6,16(5.8 \%)$ to group 7 , and 143 (52.0\%) to group 8 (Table S1). Regarding the drugs administrated during their hospital stay, $92.0 \%$ of patients were treated with corticosteroids, $91.2 \%$ with enoxaparin, $30.5 \%$ with tocilizumab, $19.3 \%$ with remdesivir, and $10.5 \%$ with interferon beta 1 . Most prevalent complications during ICU stay were superinfection 207 (75.3\%), sepsis 134 (48.7\%), and acute kidney injury 117 (42.5\%). In hospital, all-cause mortality was $52.0 \%$.

We found that $49(17.8 \%)$ of these 275 patients were positive for auto-Abs against type I IFNs (IFN- $\alpha 2$ and/or IFN- $\omega$ ) by ELISA, of which $19(6.9 \%)$ only against IFN$\alpha 2,8(2.9 \%)$ only against IFN- $\omega$, and $22(8.0 \%)$ against both. Next, we aimed to confirm the neutralizing activity of these auto-Abs. A blocking activity of $10 \mathrm{ng} / \mathrm{mL}$ was observed in $26(53.1 \%)$ of these 49 patients with positive auto-Abs against IFNs results. Auto-Abs were neutralizing against both IFN- $\alpha 2$ and IFN- $\omega$ in $21(80.8 \%)$ of these 26 patients, against only IFN- $\alpha 2$ in four patients (15.4\%), and in only one patient $(3.8 \%)$ for IFN- $\omega$.

We further assessed the clinical, analytical, and evolutive data of life-threatening COVID-19 patients admitted to the ICU depending on whether or not auto-Abs neutralizing high concentrations of type I IFNs are present 
Table 1 Main demographic, comorbidities, clinical, and laboratory data of ICU patients with severe COVID-19 infection considering the presence of positive results of auto-Abs IFN- $\alpha 2$ or auto-Abs IFN- $\omega$ obtained by ELISA and luciferase activity techniques

\begin{tabular}{|c|c|c|c|c|c|}
\hline Variable & $\begin{array}{l}\text { All results for auto- } \\
\text { Abs to type I IFNs } \\
(n=275)\end{array}$ & $\begin{array}{l}\text { Neutralizing positive results } \\
\text { for some or both auto-Abs to } \\
\text { type I IFNs } \\
(n=26)\end{array}$ & $\begin{array}{l}\text { Neutralizing negative results } \\
\text { for both auto-Abs to type I } \\
\text { IFNs } \\
(n=249)\end{array}$ & $p$-value & $\begin{array}{l}\text { OR } \\
(95 \% \mathrm{CI})\end{array}$ \\
\hline \multicolumn{6}{|l|}{ Pandemic wave } \\
\hline First; $n(\%)$ & $125(45.5)$ & $13(50.0)$ & $112(45.0)$ & 0.820 & n.a \\
\hline Second; $n(\%)$ & $23(8.4)$ & $1(3.8)$ & $22(8.8)$ & & \\
\hline Third; $n(\%)$ & $127(46.2)$ & $12(46.2)$ & $115(46.2)$ & & \\
\hline \multicolumn{6}{|l|}{ Demographics } \\
\hline Age; median (IQC) & $64(55-71)$ & $63(57-73)$ & $64(55-71)$ & 0.712 & n.a \\
\hline Sex (male); $n(\%)$ & $211(76.7)$ & $24(92.3)$ & $187(75.1)$ & 0.048 & $3.979(0.914-17.32)$ \\
\hline \multicolumn{6}{|l|}{ Comorbidities } \\
\hline Cancer; $n(\%)$ & $31(11.3)$ & $2(7.7)$ & 29 (11.6) & 0.750 & $0.632(0.142-2.815)$ \\
\hline Cardiac disease; $n(\%)$ & $44(16.0)$ & $4(15.4)$ & $40(16.1)$ & 1.000 & $0.950(0.311-2.905)$ \\
\hline $\begin{array}{l}\text { Chronic kidney disease; } \\
n(\%)\end{array}$ & $38(13.8)$ & $3(11.5)$ & $35(14.1)$ & 1.000 & $0.798(0.227-2.798)$ \\
\hline $\begin{array}{l}\text { Chronic liver disease; } \\
n(\%)\end{array}$ & $24(8.7)$ & $3(11.5)$ & $21(8.4)$ & 0.484 & $1.416(0.392-5.111)$ \\
\hline $\begin{array}{l}\text { Chronic obstructive pul- } \\
\text { monary disease; } n(\%)\end{array}$ & $45(16.4)$ & $3(11.5)$ & $42(16.9)$ & 0.590 & $0.643(0.185-2.239)$ \\
\hline Diabetes; $n(\%)$ & $78(28.4)$ & $7(26.9)$ & $71(28.5)$ & 0.864 & $0.924(0.372-2.293)$ \\
\hline Dyslipidemia; $n(\%)$ & $135(49.1)$ & $13(50.0)$ & $122(49.0)$ & 0.922 & $1.041(0.464-2.335)$ \\
\hline Hypertension; $n(\%)$ & $146(53.1)$ & $13(50.0)$ & $133(53.4)$ & 0.740 & $0.872(0.389-1.957)$ \\
\hline Obesity; $n(\%)$ & $137(49.8)$ & $11(42.3)$ & $126(50.6)$ & 0.421 & $0.716(0.316-1.620)$ \\
\hline Smoking; $n(\%)$ & $20(7.3)$ & $0(0.0)$ & $20(8.0)$ & 0.233 & n.a \\
\hline \multicolumn{6}{|l|}{ Symptom onset and admission } \\
\hline $\begin{array}{l}\text { Number of days from the } \\
\text { appearance of clinical } \\
\text { symptoms to admission } \\
\text { to the hospital; median } \\
\text { (IQR) }\end{array}$ & $8(6-11)$ & $7(6-8)$ & $8(6-11)$ & 0.009 & n.a \\
\hline $\begin{array}{l}\text { Number of days from the } \\
\text { hospital admission to } \\
\text { the ICU; median (IQR) }\end{array}$ & $2(0-6)$ & $3.5(1-7)$ & $2(0-6)$ & 0.352 & n.a \\
\hline \multicolumn{6}{|c|}{ Biological quantities at the first day in ICU } \\
\hline $\begin{array}{l}\mathrm{LEU}, \times 10^{9} \text { cells } / \mathrm{L} \\
\text { median }(\mathrm{IQR})\end{array}$ & $9.75(8.59-14.3)$ & $13.7(9.40-20.0)$ & $9.30(6.65-13.5)$ & 0.001 & n.a \\
\hline $\begin{array}{l}\mathrm{NEU}, \times 10^{9} \text { cells } / \mathrm{L} \\
\text { median }(\mathrm{IQR})\end{array}$ & $8.41(5.72-12.7)$ & $12.7(8.63-19.0)$ & $8.10(5.65-11.9)$ & 0.001 & n.a \\
\hline $\begin{array}{l}\mathrm{LYM}, \times 10^{9} \text { cells } / \mathrm{L} \\
\text { median }(\mathrm{IQR})\end{array}$ & $0.64(0.38-0.96)$ & $0.51(0.41-0.72)$ & $0.66(0.37-0.98)$ & 0.067 & n.a \\
\hline $\begin{array}{l}\mathrm{PLT}, \times 10^{9} \text { cells } / \mathrm{L} \\
\text { median }(\mathrm{IQR})\end{array}$ & $232(173-303)$ & $260.5(217-325)$ & $230(168-298)$ & 0.038 & n.a \\
\hline apH, 1; median (IQR) & $7.35(7.29-7.43)$ & $7.35(7.30-7.39)$ & $7.35(7.29-7.43)$ & 0.800 & n.a \\
\hline $\begin{array}{l}p \mathrm{aCO}_{2}, \mathrm{mmHg} ; \text { median } \\
\quad \text { (IQR) }\end{array}$ & $46(40-56.5)$ & $47(40-53)$ & $46(40-57)$ & 0.856 & n.a \\
\hline $\begin{array}{l}p \mathrm{aO}_{2}, \mathrm{mmHg} ; \text { median } \\
\quad(\mathrm{IQR})\end{array}$ & $96.5(76-125)$ & $90(73-127)$ & $97(76-124.5)$ & 0.574 & n.a \\
\hline $\mathrm{aSatO}_{2}, \%$; median (IQR) & $97.1(94.5-98.7)$ & $96.7(94.3-98.4)$ & $97.2(94.5-98.7)$ & 0.420 & n.a \\
\hline ALB, g/L; median (IQR) & $31.6(27.4-35.0)$ & $32.0(26.4-35.0)$ & $31.5(27.7-35.0)$ & 0.741 & n.a \\
\hline LDH, U/L; median (IQR) & $471.5(367.5-610.8)$ & $444.5(354-538)$ & $474.5(370-613)$ & 0.395 & n.a \\
\hline ALT, U/L; median (IQR) & $34(23-56.3)$ & $38.5(28-61)$ & $34(23-56)$ & 0.421 & n.a \\
\hline AST, U/L; median (IQR) & $45(31-64.8)$ & $41(27-52)$ & $45(32-68)$ & 0.165 & n.a \\
\hline
\end{tabular}


Table 1 (continued)

\begin{tabular}{|c|c|c|c|c|c|}
\hline Variable & $\begin{array}{l}\text { All results for auto- } \\
\text { Abs to type I IFNs } \\
(n=275)\end{array}$ & $\begin{array}{l}\text { Neutralizing positive results } \\
\text { for some or both auto-Abs to } \\
\text { type I IFNs } \\
(n=26)\end{array}$ & $\begin{array}{l}\text { Neutralizing negative results } \\
\text { for both auto-Abs to type I } \\
\text { IFNs } \\
(n=249)\end{array}$ & $p$-value & $\begin{array}{l}\text { OR } \\
(95 \% \mathrm{CI})\end{array}$ \\
\hline $\begin{array}{l}\text { BIL, } \mu \mathrm{mol} / \mathrm{L} ; \text { median } \\
\text { (IQR) }\end{array}$ & $9.2(6.5-13.9)$ & $10.4(6.0-15.0)$ & $9.0(6.7-13.7)$ & 0.819 & n.a \\
\hline $\begin{array}{l}\text { CREA, } \mu \mathrm{mol} / \mathrm{L} ; \text { median } \\
\text { (IQR) }\end{array}$ & $81(61-114)$ & $80(61-117)$ & $81(60-111)$ & 0.767 & n.a \\
\hline $\begin{array}{l}\text { UREA, mmo/L; median } \\
\text { (IQR) }\end{array}$ & $7.9(5.2-11.5)$ & $8.1(5.7-11.7)$ & $7.9(5.2-11.4)$ & 0.588 & n.a \\
\hline $\begin{array}{l}\text { TROP-T, ng/L; median } \\
\text { (IQR) }\end{array}$ & $14.7(9.4-28.2)$ & $11.3(8.4-14.7)$ & $15.8(9.8-30.9)$ & 0.121 & n.a \\
\hline $\mathrm{DD}, \mu \mathrm{g} / \mathrm{L} ;$ median $(\mathrm{IQR})$ & 879 (454-2862) & $963(482-3507)$ & $878(452-2811)$ & 0.671 & n.a \\
\hline PT, 1; median (IQR) & $1.16(1.08-1.28)$ & $1.23(1.11-1.25)$ & $1.15(1.08-1.29)$ & 0.230 & n.a \\
\hline $\begin{array}{l}\text { PROCAL, } \mu \mathrm{g} / \mathrm{L} ; \text { median } \\
\text { (IQR) }\end{array}$ & $0.26(0.13-0.68)$ & $0.29(0.14-0.51)$ & $0.26(0.13-0.73)$ & 0.875 & n.a \\
\hline $\begin{array}{l}\text { CRP, mg/L; median } \\
\text { (IQR) }\end{array}$ & $136.1(52.8-238.3)$ & $212.1(62.2-366.3)$ & $130.1(52.7-229.1)$ & 0.055 & n.a \\
\hline $\begin{array}{l}\text { FERRI, mg/L; median } \\
\text { (IQR) }\end{array}$ & $1495(874-2325)$ & 1240 (919-2389) & 1498 (862-2291) & 0.664 & n.a \\
\hline IL6, ng/L; median (IQR) & $91.3(19.5-455.2)$ & $40.4(30.2-207.9)$ & $95.3(19.7-474)$ & 0.778 & n.a \\
\hline
\end{tabular}

$O R$, odds-ratio; $C I$, confidence interval; $I C U$, intensive care unit; $I Q R$, interquartilic range; n.a., not applicable; $L E U$, number concentration of leucocytes in blood; $N E U$, number concentration of neutrophils in blood; $L Y M$, number concentration of lymphocytes in blood; PLT, number concentration of platelets in blood; $\mathrm{apH}, \mathrm{pH}$ in arterial blood; $\mathrm{paCO}_{2}$, partial pressure of carbon dioxide in arterial blood, $\mathrm{paO}_{2}$, partial pressure of oxygen in arterial blood; $\mathrm{SSatO}_{2}$, substance fraction of oxygen in arterial blood; $A L B$, mass concentration of albumin in plasma; $L D H$, catalytic concentration of lactate dehydrogenase in plasma; $A L T$, catalytic concentration of alanine transaminase in plasma; $A S T$, catalytic concentration of aspartate transaminase in plasma; BIL, substance concentration of bilirubin in plasma; $C R E A$, substance concentration of creatinine in plasma; UREA, substance concentration of urea in plasma; TROP-T, mass concentration of troponin T in plasma; $D D$, mass concentration of $\mathrm{D}$-dimer in plasma; $P T$, relative time of prothrombin in plasma; $P R O C A L$, mass concentration of procalcitonin in plasma; $C R P$, mass concentration of C-reactive protein in plasma; FERRI, mass concentration of ferritin in plasma; IL6, mass concentration of interleukin-6 in plasma

ALB, LDH, ALT, AST, BIL, CREA, UREA, TROP-T, PROCAL, CRP, FERRI, and IL6 were measured using a Cobas 6000 or Cobas 8000 analyzers (Roche Diagnostics, Risch-Rotkreuz, Switzerland). LEU, NEU, LYM, and PLT were measured using a Sysmex XN-2000 analyzer (Sysmex, Kobe, Japan), and DD, PT from ACL TOP 500 analyzer (Instrumentation Laboratory, Bedford, MA, USA). On the other hand, apH, $p \mathrm{aCO}_{2}, \mathrm{paO}_{2}$, and $\mathrm{aSatO}_{2}$ were obtained from GEM Premier 5000 gasometers (Instrumentation Laboratory)

Numbers in bold indicate a $p$-value $<0.05$

(Tables 1, 2, and 3). Table $\mathrm{S} 1$ shows the same data but classifies ICU patients following the WHO 8-point ordinal scale. Almost all the patients with positive results of neutralizing auto-Abs were men, being statistically higher than in the group of patients showing negative results (24 [92.3\%] vs. 187 [75.1]; $p=0.048$ ). No relevant differences were observed in the main comorbidities between the two groups.

The median number of days from the onset of symptoms to admission to the hospital was significantly lower in neutralizing auto-Abs group (7 [IQR 6-8] vs. 8 [IQR $6-11] ; p=0.009$ ), while the number of days from the hospital admission to the ICU (3.5 [IQR 1-7] vs. 2 [IQR $0-6] ; p=0.352$ ) was not different between the two groups. Overall, the median number of days admitted to the hospital was similar in both groups (30.5 [IQR 14-46] vs. 29 [IQR 16-50]; $p=0.819)$. The specific ICU treatment and mechanical ventilation data between both groups were not significantly different.

Regarding analytical variables, those patients with neutralizing auto-Abs showed significantly higher median values of leukocytes $\left(13.710^{9}\right.$ cells/L [IQR 9.40-20.0] vs. $9.30 \times 10^{9}$ cells/L [IQR 6.65-13.5]; $p=0.001$ ), neutrophils $\left(12.7 \times 10^{9}\right.$ cells/L [IQR $\left.8.63-19.0\right]$ vs. $8.10 \times 10^{9}$ cells $/ \mathrm{L}$ [IQR 5.65-11.9]; $p=0.001)$, platelets $\left(260.5 \times 10^{9}\right.$ cells/L [IQR 217-325] vs. $230 \times 10^{9}$ cells/L [IQR 168-298]; $p=0.038)$ ) than negative neutralizing auto-Abs patients. Furthermore, median CRP values were numerically higher (212.1 mg/L [IQR 62.2-366.3] vs. $130.1 \mathrm{mg} / \mathrm{L}$ [IQR 52.7-229.1]; $p=0.055$ ) in those patients with neutralizing auto-Abs. Drugs specifically used to treat COVID-19 at any time during admission were not different between the two groups. 
Table 2 Drugs, mechanical ventilation and other specific ICU treatments of severe COVID-19 patients admitted to ICU considering the presence of positive results of auto-Abs IFN- $\alpha 2$ or auto-Abs IFN- $\omega$ obtained by ELISA and luciferase activity techniques

\begin{tabular}{|c|c|c|c|c|c|}
\hline Variable & $\begin{array}{l}\text { All results for } \\
\text { auto-Abs to type } \\
\text { I IFNs } \\
(n=275)\end{array}$ & $\begin{array}{l}\text { Neutralizing positive results } \\
\text { for some or both auto-Abs to } \\
\text { type I IFNs } \\
(n=26)\end{array}$ & $\begin{array}{l}\text { Neutralizing negative results } \\
\text { for both auto-Abs to type I } \\
\text { IFNs } \\
(n=249)\end{array}$ & $p$-value & OR $(95 \% \mathrm{CI})$ \\
\hline \multicolumn{6}{|c|}{ Specific ICU treatment and mechanical ventilation data } \\
\hline $\begin{array}{l}\text { Patients with CRRT; } n \\
(\%)\end{array}$ & $28(10.2)$ & $3(11.5)$ & $25(10.0)$ & 0.736 & $1.169(0.328-4.170)$ \\
\hline $\begin{array}{l}\text { Patients with ECMO; } n \\
\quad(\%)\end{array}$ & $25(9.1)$ & $2(7.7)$ & $23(9.2)$ & 1.000 & $0.819(0.182-3.688)$ \\
\hline $\begin{array}{l}p \mathrm{aO}_{2} / \mathrm{FiO}_{2}, \mathrm{mmHg} / \% ; \\
\text { median (IQR) }\end{array}$ & $116.5(86-166)$ & $111(85-153)$ & $120(86.5-167)$ & 0.313 & n.a \\
\hline $\begin{array}{l}\text { Patients treated with IMV; } \\
n(\%)\end{array}$ & $232(84.4)$ & $22(84.6)$ & $210(84.3)$ & 1.000 & $1.021(0.334-3.127)$ \\
\hline $\begin{array}{l}\text { Patients with nitric oxide } \\
\text { administration during } \\
\text { IMV; } n(\%)\end{array}$ & $38(13.8)$ & $4(15.4)$ & $34(13.7)$ & 0.767 & $1.150(0.373-3.542)$ \\
\hline $\begin{array}{l}\text { Patients positioned in } \\
\text { prone position during } \\
\text { IMV; } n(\%)\end{array}$ & $205(74.5)$ & $18(69.2)$ & $187(75.1)$ & 0.513 & $0.746(0.309-1.800)$ \\
\hline $\begin{array}{l}\text { Number of days with } \\
\text { IMV; median (IQR) }\end{array}$ & $13(4-27)$ & $11(3-17)$ & $13(4-28)$ & 0.291 & n.a \\
\hline \multicolumn{6}{|l|}{ Drugs administration } \\
\hline $\begin{array}{l}\text { Patients treated with } \\
\text { hydroxychloroquine; } \\
n(\%)\end{array}$ & $126(45.8)$ & $13(50.0)$ & $113(45.4)$ & 0.653 & $1.204(0.536-2.701)$ \\
\hline $\begin{array}{l}\text { Patients treated with lopi- } \\
\text { navir/ritonavir; } n(\%)\end{array}$ & 85 (30.9) & $11(42.3)$ & $74(29.7)$ & 0.186 & $1.734(0.761-3.954)$ \\
\hline $\begin{array}{l}\text { Patients treated with } \\
\text { remdesivir; } n(\%)\end{array}$ & $53(19.3)$ & $5(19.2)$ & $48(19.3)$ & 0.995 & $0.997(0.358-2.778)$ \\
\hline $\begin{array}{l}\text { Patients treated with } \\
\text { azithromycin; } n(\%)\end{array}$ & $69(25.1)$ & $5(19.2)$ & $64(25.7)$ & 0.469 & $0.688(0.249-1.901)$ \\
\hline $\begin{array}{l}\text { Patients treated with } \\
\text { tocilizumab; } n(\%)\end{array}$ & $84(30.5)$ & $9(34.6)$ & $75(30.1)$ & 0.636 & $1.228(0.524-2.880)$ \\
\hline $\begin{array}{l}\text { Patients treated with corti- } \\
\text { costeroids; } n(\%)\end{array}$ & $253(92.0)$ & $25(96.2)$ & $228(91.6)$ & 0.705 & $2.303(0.297-17.85)$ \\
\hline $\begin{array}{l}\text { Patients treated with inter- } \\
\text { feron beta } 1 ; n(\%)\end{array}$ & $29(10.5)$ & $3(11.5)$ & $26(10.4)$ & 0.744 & $1.119(0.314-3.983)$ \\
\hline $\begin{array}{l}\text { Patients treated with } \\
\text { enoxaparin; } n(\%)\end{array}$ & $250(91.2)$ & $26(100.0)$ & $224(90.3)$ & 0.144 & n.a \\
\hline $\begin{array}{l}\text { Patients treated with } \\
\text { anticoagulants } \\
\text { with prophylactic or thera- } \\
\text { peutic goal; } n(\%)\end{array}$ & $275(100)$ & $26(100.0)$ & $249(100.0)$ & n.a & n.a \\
\hline
\end{tabular}

$O R$, odds-ratio; $C I$, confidence interval; $I C U$, intensive care unit; $I Q R$, interquartilic range; n.a., not applicable; $C R R T$, continuous renal replacement therapy; ECMO, extracorporeal membrane oxygenation; $I M V$, invasive mechanical ventilation; $\mathrm{FiO}_{2}$, fraction of inspired oxygen; $\mathrm{paO}$, partial pressure of oxygen in arterial blood

Numbers in bold indicate a $p$-value $<0.05$

No significant association between the presence of neutralizing auto-Abs and mortality (12 [46.2\%] vs. 131 [52.6\%]; $p=0.531$ ) or other complications was found (Table 3), except for acute kidney injury (AKI) (17 [65.4\%] vs. 100 [40.2\%]; $p=0.013$ ). Patients with positive autoAbs showed approximately three times more probability to present AKI (OR 2.814 [95\%CI 1.207-6.563]) than those with negative results. Significant differences were observed in patients at KDIGO-AKI stages $1(p<0.001), 2$ $(p<0.001)$, and $3(p<0.001)$ when they were compared with those patients with non AKI. AKI was significantly higher in neutralizing auto-Abs patients who finally died (12 [100\%] 
Table 3 Length of hospital and ICU stay, and complications of severe COVID-19 patients admitted to ICU considering the presence of positive results of auto-Abs IFN- $\alpha 2$ or auto-Abs IFN- $\omega$ obtained by ELISA and Luciferase activity techniques

\begin{tabular}{|c|c|c|c|c|c|}
\hline Variable & $\begin{array}{l}\text { All results for } \\
\text { auto-Abs to type } \\
\text { I IFNs } \\
(n=275)\end{array}$ & $\begin{array}{l}\text { Neutralizing positive results } \\
\text { for some or both auto-Abs to } \\
\text { type I IFNs } \\
(n=26)\end{array}$ & $\begin{array}{l}\text { Neutralizing negative results } \\
\text { for both auto-Abs to type I } \\
\text { IFNs } \\
(n=249)\end{array}$ & $p$-value & OR $(95 \% \mathrm{CI})$ \\
\hline \multicolumn{6}{|l|}{ Length of hospital and ICU stay } \\
\hline $\begin{array}{l}\text { Number of admitted days } \\
\text { to the ICU; median } \\
\text { (IQR) }\end{array}$ & $15(7-31)$ & $13.5(4-24)$ & $15(7-31)$ & 0.500 & n.a \\
\hline $\begin{array}{l}\text { Number of admitted days } \\
\text { to the hospital; median } \\
\text { (IQR) }\end{array}$ & $29(15-49)$ & $30.5(14-46)$ & $29(16-50)$ & 0.819 & n.a \\
\hline \multicolumn{6}{|l|}{ Complications during ICU stay } \\
\hline $\begin{array}{l}\text { Patients with neurological } \\
\text { complications; } n(\%)\end{array}$ & $77(28.0)$ & $5(19.2)$ & $72(28.9)$ & 0.295 & $0.585(0.213-1.612)$ \\
\hline $\begin{array}{l}\text { Patients with thrombotic } \\
\text { complications; } n(\%)\end{array}$ & $50(18.2)$ & $5(19.2)$ & $45(18.1)$ & 0.795 & $1.079(0.389-3.015)$ \\
\hline $\begin{array}{l}\text { Patients with hemorrhagi- } \\
\text { cal complications; } n(\%)\end{array}$ & $27(9.8)$ & $4(15.4)$ & $23(9.2)$ & 0.301 & $1.787(0.567-5.634)$ \\
\hline $\begin{array}{l}\text { Patients with cardiovascu- } \\
\text { lar complications; } n(\%)\end{array}$ & $56(20.4)$ & $5(19.2)$ & $51(20.5)$ & 0.880 & $0.924(0.332-2.570)$ \\
\hline $\begin{array}{l}\text { Patients with acute kidney } \\
\text { injury; } n(\%)\end{array}$ & $117(42.5)$ & $17(65.4)$ & $100(40.2)$ & 0.013 & $2.814(1.207-6.563)$ \\
\hline $\begin{array}{l}\text { Patients with superinfec- } \\
\text { tion; } n(\%)\end{array}$ & $207(75.3)$ & $19(73.1)$ & $188(75.5)$ & 0.785 & $0.881(0.353-2.195)$ \\
\hline Patients with sepsis; $n(\%)$ & $134(48.7)$ & $11(42.3)$ & $123(49.4)$ & 0.491 & $0.751(0.332-1.700)$ \\
\hline $\begin{array}{l}\text { Patients with septic } \\
\text { shock; } n(\%)\end{array}$ & $70(25.5)$ & $4(15.4)$ & $66(26.5)$ & 0.215 & $0.504(0.167-1.517)$ \\
\hline $\begin{array}{l}\text { Patients with multiple } \\
\text { organ failure; } n(\%)\end{array}$ & $56(20.4)$ & $5(19.2)$ & $51(20.5)$ & 0.880 & $0.924(0.332-2.570)$ \\
\hline \multicolumn{6}{|l|}{ Final status } \\
\hline Exitus; $n(\%)$ & $143(52.0)$ & $12(46.2)$ & $131(52.6)$ & 0.531 & $0.772(0.343-1.736)$ \\
\hline
\end{tabular}

$O R$, odds-ratio; $C I$, confidence interval; $I C U$, intensive care unit; $I Q R$, interquartilic range; n.a., not applicable

Numbers in bold indicate a $p$-value $<0.05$

vs. 60 [45.8\%]; $p<0.001)$, but not in the rest of the 8-point ordinal scale groups (Table S1). When AKI-related variables were selected and a binary logistic regression analysis was performed, a higher risk of AKI was independently associated with the presence of type I IFNs neutralizing auto-Abs (multivariate OR 7.672 [95\% CI 2.286-25.75]), as well as, a glomerular filtrate rate $(\mathrm{GFR})<60 \mathrm{~mL} / \mathrm{min} / 1.73 \mathrm{~m}^{2}$ at hospital admission, the need for ECMO, the development of multiple organ failure, the seventh and eighth points of the ordinal scale, and the use of interferon beta 1 during ICU admission (Table S2).

\section{Discussion}

From March 2020 to March 2021, a sample of 275 ICU patients could be tested for type I IFNs auto-Abs $(\alpha 2$ and $\omega)$, representing $70.5 \%$ of all patients admitted to the ICU during the study period. One-fifth (49 (17.8\%)) showed positive results, with blocking activity in half of them (26 $(9.5 \%))$. There were no relevant differences in the main demographic, comorbidities, and clinical data. Patients with positive neutralizing auto-Abs had a significantly higher leukocytes, neutrophils, and platelet values than negative ones. Interestingly, acute kidney injury was also significantly more frequent in positive patients. Overall, half of these patients (52.0\%) died without significant differences between positive and negative neutralizing auto-Abs groups.

A recent study by Koning et al. [14] showed that autoAbs against IFN- $\alpha 2$ and IFN- $\omega$ tested by multiplex particle-based assay and ELISA were found in $35(16.6 \%)$ out of 210 COVID-19 patients, of whom 6 (17.1\%) out of 35 had neutralizing auto-Abs using STAT1 phosphorylation assay. Eighty-eight (41.9\%) of these 210 COVID-19 patients were admitted to ICU, belonging all 6 patients with neutralizing auto-Abs to this group of greater severity. Accordingly, 
Bastard et al. [13] reported that auto-Abs against IFN- $\alpha 2$ and IFN- $\omega$ were detected in $135(13.7 \%)$ out of 987 lifethreatening COVID-19 patients, showing blocking activity in 101 (74.8\%) of these 135 ones. Altogether, these findings suggest that the greater the severity, the higher the proportion of neutralizing antibodies, but even in the critically ill COVID-19 patients, it is important to determine the blocking activity against type I IFNs. In our cohort, half (53.1\%) of auto-Abs determined by ELISA showed blocking activity for $10 \mathrm{ng} / \mathrm{mL}$ of IFNs using luciferase reporter assays.

According to previous reports [13-17], type I IFN neutralizing auto-Abs may help physicians to identify patients at higher-risk to develop severe COVID-19, at the early stages of the disease. However, there is still limited data on whether characteristics of ICU patients with neutralizing IFN auto-Abs are different from those ICU patients without these auto-Abs. Our results did not show demographic, comorbidity or clinical differences between both groups, except for an excess of men in patients with auto-Abs positive results. It could be explained because an inadequate type I IFN response is a common feature in critical COVID-19 patients $[5,9,25,26]$ regardless of whether this defect is due to auto-Abs against type I IFNs [15, 17], rare inborn errors of immunity, or any other mechanism.

However, some laboratory differences were detected in our COVID-19 patients admitted to ICU considering the presence of neutralizing IFN auto-Abs. Higher CRP values were close to statistical significance in the group of patients with neutralizing auto-Abs, as reported by Troya et al. in a smaller group of ICU patients [16]. In addition, our patients with auto-Abs positive results also showed significantly higher leukocytes, neutrophils, and platelet values. All these blood parameters have been used to stratify patients at higher risk for COVID-19 complications $[8,9]$ suggesting that positive neutralizing auto-Abs patients may develop more severe forms of COVID-19.

In contrast with previously described in smaller cohorts $[14,16]$, mortality in our patients was not different between those ICU patients with and without neutralizing type I IFNs auto-Abs. Interestingly, we found a significant association between AKI and neutralizing type I IFNs auto-Abs. AKI can be caused by several mechanisms in critical COVID-19 patients [27], and it should be determined if these auto-Abs play a role in its pathogenesis. It is possible, but only speculative, that type I IFN auto-Abs predisposes to the formation of immune complexes that in turn activate complement. The abnormal presence of plasma-derived complement components in the tubular lumen leads to the assembly of the C5b-9 in the tubular epithelial cells, and it could be involved in the pathogenesis of tubulointerstitial damage. In this regard, a retrospective series of six post-mortem COVID-19 patients showed complement C5b-9 deposition on tubules in all kidneys examined [28]. Although, these findings have to be confirmed, neutralizing IFN auto-Abs might be a biomarker to identify those critical COVID-19 patients with greater risk of developing AKI, helping physicians to make earlier preventive and therapeutic decisions.

Unlike other factors related to increased COVID-19 severity, detection of neutralizing type I IFNs auto-Abs in ICU patients may pave the way for specific therapeutic interventions. In this regard, plasmapheresis was recently reported to decrease the titers of blood auto-Abs in four hospitalized patients with life-threatening COVID-19 pneumonia, even though mortality still was 50\% [19]. Little is also known whether the administration of IFN- $\beta$, B-cell depletion, or other therapies might be beneficial to treat these patients with auto-Abs against type I IFNs admitted to ICU [20].

Our study has several limitations that deserve further comment. First, it was not possible to obtain plasma samples from all the patients admitted to the ICU during the study period, although we were able to analyze more than $70 \%$ of them. Nevertheless, this was a representative group with little potential for bias. Second, we exclusively detected the most frequent type I IFNs ( $\alpha 2$ and $\omega$ ) by ELISA, and, therefore, it is possible that some study patients presented other antibodies that were not detected (i.e., auto-Abs against IFN$\beta)$. Third, we analyzed blocking activity for $10 \mathrm{ng} / \mathrm{mL}$ of IFNs according with previous reports [13-16], but blood IFN- $\alpha$ concentrations of mild/moderate COVID-19 patients typically range from 1 to $100 \mathrm{pg} / \mathrm{mL}$, and they are even lower in severe and critical ones [25], so auto-Abs neutralizing concentrations of type I IFNs below $10 \mathrm{ng} / \mathrm{mL}$ may underlie life-threatening COVID-19 pneumonia in more than 9.5\% of cases, as suggested by a recent study [Bastard in press]. Fourth, since our study was retrospective, confounders could be overlooked, and missing data might have altered some results. Fifth, the study design does not permit us to establish if the antibodies play a pathogenic role or are simply a biomarker of increased risk for developing renal failure among such patients. Finally, the present study does not allow assessing the usefulness of auto-Abs in those patients at earlier or milder stages of the disease.

In summary, one-fifth of COVID-19 patients admitted to ICU presented auto-Abs against type I IFNs (IFN- $\alpha 2$ and/or IFN- $\omega$ ), and blocking activity against $10 \mathrm{ng} / \mathrm{mL}$ of type I IFNs in half of them. In such life-threatening COVID-19 population, the presence of neutralizing IFNs auto-Abs was remarkably and statistically greater in men, associated with increased inflammatory laboratory parameters related to COVID-19 severity, and also related with a higher risk for developing acute kidney injury. Conversely, mortality between both groups was not different. Therefore, the early identification of these auto-Abs help to identify a significant proportion of patients at higher risk to develop critical COVID-19 pneumonia, its usefulness being more limited when patients are in the ICU. Further 
research is needed to assess the clinical and pathogenic role of neutralizing auto-Abs against type I IFNs in order to better select the most appropriate therapies.

Supplementary Information The online version contains supplementary material available at https://doi.org/10.1007/s10875-021-01136-x.

Author Contribution XS and RR-B contributed equally to this work. XS, RR-B, FM, and JS-R devised the study. XS, RR-B, FM, and JS-R had full access to all of the data in the study and take responsibility for the integrity of the data and the accuracy of the data analysis. XS, RR-B, VDG, PB, AR-M, XC, JLC, FM, and JS-R provided input on the trial design. XS, VDG, XLP-F, MPF-C, MAG-B, GS-C, EB-H, AA, GR-B, and JS-R assisted in patient management. RR-B, PB, JR, $\mathrm{QP}, \mathrm{RC}, \mathrm{JLC}$, and FM designed and performed the laboratory analysis. XS, RR-B, VDG, FM, and JS-R were responsible for acquiring, analyzing, and interpreting data. XS, RR-B, PB, FM, and JS-R drafted the manuscript. VDG, JR, QP, XLP-F, AR-M, RC, XC, and JLC critically revised the manuscript. XS and RR-B contributed to the statistical analysis. XS, RR-B, FM, and JS-R verified the underlying data. All authors contributed to conducting the trial and read and approved the final manuscript.

Funding With the support of the Departament de Salut de la Generalitat de Catalunya, we thank CERCA Programme/Generalitat de Catalunya for institutional support. HUB-IDIBELL investigators are supported by La Marató de TV3 foundation (202115-30-31). The Laboratory of Human Genetics of Infectious Diseases is supported by the Howard Hughes Medical Institute, the Rockefeller University, the St. Giles Foundation, the National Institutes of Health (NIH) (R01AI088364), the National Center for Advancing Translational Sciences (NCATS), NIH Clinical and Translational Science Award (CTSA) program (UL1 TR001866), a Fast Grant from Emergent Ventures, Mercatus Center at George Mason University, the Yale Center for Mendelian Genomics and the GSP Coordinating Center funded by the National Human Genome Research Institute (NHGRI) (UM1HG006504 and U24HG008956), the Yale High Performance Computing Center (S10OD018521), the Fisher Center for Alzheimer's Research Foundation, the Meyer Foundation, the French National Research Agency (ANR) under the "Investments for the Future" program (ANR-10-IAHU-01), the Integrative Biology of Emerging Infectious Diseases Laboratory of Excellence (ANR10-LABX-62-IBEID), the French Foundation for Medical Research (FRM) (EQU201903007798), the FRM and ANR GENCOVID project, the ANRS-COV05, ANR GENVIR (ANR-20-CE93-003) and ANR AABIFNCOV (ANR-20-CO11-0001) projects, the European Union's Horizon 2020 research and innovation programme under grant agreement No 824110 (EASI-genomics), the Square Foundation, GrandirFonds de solidarité pour l'enfance, the Fondation du Souffle, the SCOR Corporate Foundation for Science, Institut National de la Santé et de la Recherche Médicale (INSERM), and the University of Paris. PB and $\mathrm{JR}$ were supported by the MD-PhD program of the Imagine Institute (with the support of the Fondation Bettencourt-Schueller).

Availability of Data and Material The raw data supporting the conclusions of this article will be made available by the authors, without undue reservation.

Code Availability Not applicable.

\section{Declarations}

Ethics Approval Ethical approval for the study was obtained from the Hospital Universitari de Bellvitge - IDIBELL (L'Hospitalet de Llobregat, Barcelona, Spain) Research Ethics Committee (approval number PR40/21). Informed consent was waived due to the study's retrospective nature and the mandatory isolation measures applied during in-hospital care.

Consent to Participate Not applicable.

Consent for Publication Not applicable.

Conflict of Interest The authors declare no competing interests.

\section{References}

1. Lai CC, Shih TP, Ko WC, Tang HJ, Hsueh PR. Severe acute respiratory syndrome coronavirus 2 (SARS-CoV-2) and coronavirus disease-2019 (COVID-19): the epidemic and the challenges. Int J Antimicrob Agents. 2020;17: 105924. https://doi.org/10.1016/j. ijantimicag.2020.105924.

2. Wang L, Wang Y, Ye D, Liu Q. Review of the 2019 novel coronavirus (SARS-CoV-2) based on current evidence. Int J Antimicrob Agents. 2020;19: 105948. https://doi.org/10.1016/j.ijantimicag. 2020.105948.

3. WHO Director-General's opening remarks at the media briefing on COVID-19 - 11 March 2020. https://www.who.int/dg/speec hes/detail/who-director-general-s-opening-remarks-at-the-mediabriefing-on-covid-19---11-march-2020. Accessed 14 Jun 2021.

4. Levin AT, Hanage WP, Owusu-Boaitey N, Cochran KB, Walsh SP, Meyerowitz-Katz G. Assessing the age specificity of infection fatality rates for COVID-19: systematic review, meta-analysis, and public policy implications. Eur J Epidemiol. 2020;35(12):112338. https://doi.org/10.1007/s10654-020-00698-1.

5. Zhang Q, Bastard P, Bolze A, Jouanguy E, Zhang SY, Cobat A, et al. Life-threatening COVID-19: defective interferons unleash excessive inflammation. Med (N Y). 2020;1(1):14-20. https://doi. org/10.1016/j.medj.2020.12.001.

6. Rubio-Rivas M, Ronda M, Padulles A, Mitjavila F, Riera-Mestre A, García-Forero C, et al. Beneficial effect of corticosteroids in preventing mortality in patients receiving tocilizumab to treat severe COVID-19 illness. Int J Infect Dis. 2020;101:290-7. https://doi.org/10.1016/j.ijid.2020.09.1486.

7. Huang C, Wang Y, Li X, Ren L, Zhao J, Hu Y, et al. Clinical features of patients infected with 2019 novel coronavirus in Wuhan, China. Lancet. 2020;395(10223):497-506. https://doi.org/10. 1016/S0140-6736(20)30183-5.

8. Wu C, Chen X, Cai Y, Xia J, Zhou X, Xu S, et al. Risk factors associated with acute respiratory distress syndrome and death in patients with coronavirus disease 2019 pneumonia in Wuhan, China. JAMA Intern Med. 2020;180(7):934-43. https://doi.org/ 10.1001/jamainternmed.2020.0994.

9. Vabret N, Britton GJ, Gruber C, Hegde S, Kim J, Kuksin M, et al. Immunology of COVID-19: current state of the science. Immunity. 2020;52(6):910-41. https://doi.org/10.1016/j.immuni.2020. 05.002.

10. Anastassopoulou C, Gkizarioti Z, Patrinos GP, Tsakris A. Human genetic factors associated with susceptibility to SARS-CoV-2 infection and COVID-19 disease severity. Hum Genomics. 2020;14(1):40. https://doi.org/10.1186/s40246-020-00290-4.

11. Novelli G, Biancolella M, Mehrian-Shai R, Colona VL, Brito AF, Grubaugh ND, et al. COVID-19 one year into the pandemic: 
from genetics and genomics to therapy, vaccination, and policy. Hum Genomics. 2021;15(1):27. https://doi.org/10.1186/ s40246-021-00326-3.

12. Zhang Q, Bastard P, Liu Z, Le Pen J, Moncada-Velez M, Chen $\mathrm{J}$, et al. Inborn errors of type I IFN immunity in patients with life-threatening COVID-19. Science. 2020;370(6515):eabd4570. https://doi.org/10.1126/science.abd4570.

13 Bastard P, Rosen LB, Zhang Q, Michailidis E, Hoffmann HH, Zhang Y, et al. Autoantibodies against type I IFNs in patients with lifethreatening COVID-19. Science. 2020;370(6515):eabd4585. https://doi.org/10.1126/science.abd4585.

14. Koning R, Bastard P, Casanova JL, Brouwer MC, van de Beek D, et al. Autoantibodies against type I interferons are associated with multi-organ failure in COVID-19 patients. Intensive Care Med. 2021;9:1-3. https://doi.org/10.1007/s00134-021-06392-4.

15 van der Wijst MGP, Vazquez SE, Hartoularos GC, Bastard P, Grant T, Bueno R, et al. Longitudinal single-cell epitope and RNA-sequencing reveals the immunological impact of type 1 interferon autoantibodies in critical COVID-19. bioRxiv [Preprint]. 2021 Mar 10:2021.03.09.434529. https://doi.org/10.1101/ 2021.03.09.434529.

16. Troya J, Bastard P, Planas-Serra L, Ryan P, Ruiz M, de Carranza $\mathrm{M}$, et al. Neutralizing autoantibodies to type I IFNs in $>10 \%$ of patients with severe COVID-19 pneumonia hospitalized in Madrid, Spain. J Clin Immunol. 2021;13:1-9. https://doi.org/10. 1007/s10875-021-01036-0.

17. Wang EY, Mao T, Klein J, Dai Y, Huck JD, Jaycox JR, et al. Diverse functional autoantibodies in patients with COVID19. Nature. 2021;595(7866):283-8. https://doi.org/10.1038/ s41586-021-03631-y.

18. Bastard P, Lévy R, Henriquez S, Bodemer C, Szwebel TA, Casanova JL. Interferon- $\beta$ therapy in a patient with incontinentia pigmenti and autoantibodies against type I IFNs infected with SARS-CoV-2. J Clin Immunol. 2021;25:1-3. https://doi.org/10. 1007/s10875-021-01023-5.

19. de Prost N, Bastard P, Arrestier R, Fourati S, Mahévas M, Burrel $\mathrm{S}$, et al. Plasma exchange to rescue patients with autoantibodies against type I interferons and life-threatening COVID-19 pneumonia. J Clin Immunol. 2021;41(3):536-44. https://doi.org/10.1007/ s10875-021-00994-9.

20. Vinh DC, Abel L, Bastard P, Cheng MP, Condino-Neto A, Gregersen PK, et al. Harnessing type I IFN immunity against SARS-CoV-2 with early administration of IFN- $\beta$. J Clin Immunol. 2021;8:1-18. https://doi.org/10.1007/s10875-021-01068-6.

21 Schulman S, Kearon C; Subcommittee on control of anticoagulation of the scientific and standardization committee of the international society on thrombosis and haemostasis. Definition of major bleeding in clinical investigations of antihemostatic medicinal products in non-surgical patients. J Thromb Haemost. 2005;3(4):692-4. https://doi.org/10.1111/j.1538-7836.2005. 01204.x.

22 Kellum JA, Lameire N, KDIGO AKI Guideline Work Group. Diagnosis, evaluation, and management of acute kidney injury: a KDIGO summary (Part 1). Crit Care. 2013;17(1):204. https://doi. org/10.1186/cc11454.

23. Singer M, Deutschman CS, Seymour CW, Shankar-Hari M, Annane D, Bauer M, Bellomo R, Bernard GR, Chiche JD, Coopersmith CM, Hotchkiss RS, Levy MM, Marshall JC, Martin GS, Opal SM, Rubenfeld GD, van der Poll T, Vincent JL, Angus DC. The third international consensus definitions for sepsis and septic shock (Sepsis-3). JAMA. 2016;315(8):801-10. https://doi.org/10. 1001/jama.2016.0287.

24. Vincent JL, Moreno R, Takala J, Willatts S, De Mendonça A, Bruining H, et al. The SOFA (Sepsis-related Organ Failure Assessment) score to describe organ dysfunction/failure. On behalf of the working group on sepsis-related problems of the European Society of Intensive Care Medicine. Intensive Care Med. 1996;22(7):70710. https://doi.org/10.1007/BF01709751.

25. Hadjadj J, Yatim N, Barnabei L, Corneau A, Boussier J, Smith $\mathrm{N}$, et al. Impaired type I interferon activity and inflammatory responses in severe COVID-19 patients. Science. 2020;369(6504):718-24. https://doi.org/10.1126/science.abc6027.

26. Bastard P, Zhang Q, Cobat A, Jouanguy E, Zhang SY, Abel L, et al. Insufficient type I IFN immunity underlies life-threatening COVID-19 pneumonia. C R Biol. 2021;344(1):19-25. https://doi. org/10.5802/crbiol.36.

27. Kellum JA, van Till JWO, Mulligan G. Targeting acute kidney injury in COVID-19. Nephrol Dial Transplant. 2020;35(10):165262. https://doi.org/10.1093/ndt/gfaa231.

28. Diao B, Wang C, Wang R, Feng Z, Zhang J, Yang H, et al. Human kidney is a target for novel severe acute respiratory syndrome coronavirus 2 infection. Nat Commun. 2021;12(1):2506. https:// doi.org/10.1038/s41467-021-22781-1.

Publisher's Note Springer Nature remains neutral with regard to jurisdictional claims in published maps and institutional affiliations.

\section{Authors and Affiliations}

\section{Xavier Solanich ${ }^{1,2}$ D $\cdot$ Raúl Rigo-Bonnin ${ }^{2,3} \cdot$ Victor-David Gumucio $^{2,4} \cdot$ Paul Bastard $^{5,6,7} \cdot$ Jérémie Rosain ${ }^{5,6}$. Quentin Philippot ${ }^{5,6} \cdot$ Xosé-Luis Perez-Fernandez $^{2,4} \cdot$ Maria-Paz Fuset-Cabanes $^{2,4} \cdot$ Miguel-Ángel Gordillo-Benitez $^{2,4}$. Guillermo Suarez-Cuartin ${ }^{2,8}$. Enric Boza-Hernandez ${ }^{2,9} \cdot$ Antoni Riera-Mestre $^{1,2,10}$ - Alba Parra-Martínez ${ }^{11,12}$. Roger Colobran ${ }^{13,14,15}$. Arnau Antolí, ${ }^{1,2}$ Sergio Navarro ${ }^{2,16} \cdot$ Gemma Rocamora-Blanch $^{1,2} \cdot$ Mario Framil $^{2,16}$. Laura Calatayud ${ }^{2,17} \cdot$ Xavier Corbella $^{1,2,18}$. Jean-Laurent Casanova ${ }^{5,6,7,19} \cdot$ Francisco Morandeira $^{2,16}$. Joan Sabater-Riera ${ }^{2,4}$}

1 Department of Internal Medicine, Hospital Universitari de Bellvitge, L'Hospitalet de Llobregat, Barcelona, Spain

2 Bellvitge Biomedical Research Institute (IDIBELL), L'Hospitalet de Llobregat, Barcelona, Spain

3 Department of Clinical Laboratory, Hospital Universitari de Bellvitge, L'Hospitalet de Llobregat, Barcelona, Spain
4 Department of Intensive Care, Hospital Universitari de Bellvitge, L'Hospitalet de Llobregat, Barcelona, Spain

5 Laboratory of Human Genetics of Infectious Diseases, Necker Branch, INSERM U1163, Necker Hospital for Sick Children, Paris, EU, France

6 Imagine Institute, University of Paris, Paris, EU, France 
7 St. Giles Laboratory of Human Genetics of Infectious Diseases, Rockefeller Branch, The Rockefeller University, New York, NY, USA

8 Department of Respiratory Medicine, Hospital Universitari de Bellvitge, L'Hospitalet de Llobregat, Barcelona, Spain

9 Department of Anesthesiology, Hospital Universitari de Bellvitge, L'Hospitalet de Llobregat, Barcelona, Spain

10 Faculty of Medicine and Health Sciences, Universitat de Barcelona, Barcelona, Spain

11 Infection in Immunocompromised Pediatric Patients Research Group, Vall d'Hebron Institut de Recerca (VHIR), Vall d'Hebron Barcelona Hospital Campus, Barcelona, Spain

12 Pediatric Infectious Diseases and Immunodeficiencies Unit, Hospital Universitari Vall d'Hebron, Vall d'Hebron Barcelona Hospital Campus, Barcelona, Spain

13 Immunology Division, Genetics Department, Hospital Universitari Vall d'Hebron, Vall d'Hebron Barcelona Hospital Campus, Barcelona, Spain
14 Diagnostic Immunology Research Group, Vall d'Hebron Institut de Recerca (VHIR), Vall d' Hebron Barcelona Hospital Campus, Barcelona, Spain

15 Immunology Unit. Department of Cellular Biology, Physiology and Immunology, Universitat Autònoma de Barcelona (UAB), Barcelona, Spain

16 Department of Immunology, Hospital Universitari de Bellvitge, L'Hospitalet de Llobregat, Barcelona, Spain

17 Department of Microbiology, Hospital Universitari de Bellvitge, L'Hospitalet de Llobregat, Barcelona, Spain

18 School of Medicine, Universitat Internacional de Catalunya, Barcelona, Spain

19 Howard Hughes Medical Institute, New York, NY, USA 